\title{
Sobre Ensino e Pesquisa
}

About Teaching and Research

Rafael Faraco Benthien, ,**

FAGUNDES, Bruno Flávio Lontra. O Auge da História. História do curso de História da Universidade Federal do Paraná. São Paulo: Letra e Voz, 2019. 182 p.

Nota-se, nas últimas duas décadas, um adensamento nos esforços em prol da historicização dos cursos de História no Brasil. Constituem sua forma mais visível e direta os estudos de caso, em que se combinam, de maneiras variadas, histórias institucionais e políticas, bem como análises de programas e estudos populacionais (em particular, de docentes). ${ }^{1}$ Não menos significativas, contudo, são as investigações de aspectos outros, indiretos, que reverberam na compreensão da história dos cursos. Seja analisando trajetórias de indivíduos ou grupos ${ }^{2}$, seja apostando na etnografia de práticas que acompanham a criação de tais espaços ${ }^{3}$, esse segundo conjunto de trabalhos ajuda a dimensionar com maior precisão a complexidade de objetos de estudo que nos são, ao mesmo tempo, próximos e caros.

É no cruzamento dessas duas sendas que vem se situar O Auge da História, livro escrito por Bruno Flávio Lontra Fagundes e dedicado ao estudo do curso de História da atual Universidade Federal do Paraná (doravante UFPR). Trata-se de mais uma inflexão na versátil e multidisciplinar trajetória de seu autor, que explorou, antes, o "livro-arquivo" de José Pedro Xavier da Veiga (2014a), ou então as representações do Brasil e de sua história na literatura contemporânea (2010 e 2011). Professor da Universidade Estadual do Paraná (UNESPAR) desde 2015, Fagundes apresenta nele as conclusões de um estágio pós-doutoral realizado na Universidade Federal do Rio de Janeiro, em alguma medida prefiguradas em artigos científicos já conhecidos na área (2014b e 2017).

O livro em tela analisa os 50 anos iniciais do curso de História da UFPR. Tendo aberto suas portas em 1938, ainda como curso de Geografia e História em uma faculdade isolada (a Faculdade de Filosofia, Ciências e Letras do Para-

\footnotetext{
* O presente trabalho foi realizado com apoio da Coordenação de Aperfeiçoamento de Pessoal de Nível Superior - Brasil (CAPES) - Código de Financiamento 001.

** Universidade Federal do Paraná (UFPR), Curitiba, PR, Brasil. rfbenthien@ufpr.br <https://orcid. org/0000-0001-8342-3217>
} 
ná), ele passa a diplomar turmas formadas apenas por historiadores em 1964, muitos anos após a reunificação da Universidade do Paraná (1946) e a sua federalização (1950). A partir de 1972, o curso passa a conviver com um dos primeiros mestrados abertos e reconhecidos oficialmente.

Uma tese norteia o livro e dá a ele dimensão militante, qual seja: a de que o curso de História instalado em Curitiba sacrifica o ensino em prol da sobrevalorização da pesquisa. Tal conclusão almeja ser útil ao presente, pois oferece subsídios para que se possa refletir, a partir de um estudo de caso, acerca do caráter generalizado dessa desvinculação entre ensino e pesquisa. O "auge" da história assume, assim, contornos algo paradoxais e irônicos. Ao profissionalizar o ofício, inclusive instituindo um Programa de Pós-graduação inovador, os historiadores da UFPR queimaram as pontes entre o mundo e a universidade, isolando-a no que seria o inverso de uma história pública. Como essa instituição encontra-se novamente sob ataque, o autor sugere que rever os erros passados, ainda tão presentes, se faz necessário para a construção de um futuro melhor.

Para defender tal tese, o autor divide o livro em duas partes. A primeira, composta de dois capítulos, tem expressão cronológica: ela fornece subsídios factuais e legais para que o leitor entenda como se estabeleceu o curso de Geografia e História na Faculdade de Filosofia, Ciências e Letras do Paraná (doravante FFCL), bem como quais foram seus principais expoentes. Nota-se a pouca preocupação com a produção de conhecimento científico original. Apenas um dos catedráticos de primeira hora, o professor Brasil Pinheiro Machado (1907-1997), destoa dos colegas, defendendo a ciência como base da vida universitária (o que lhe garante na obra, aliás, o rótulo de "enigma"). Esse momento inicial revela um ensino superior mundano, em que imperam preocupações de ordem moral, com uma ancoragem cristã e política, reunindo setores da elite do Estado do Paraná. Tal caldo é propício para uma defesa do sacerdócio do ensino. Era ao professorado, afinal, que se dirigia a maioria dos formandos. Em contrapartida, uma segunda geração, amparada pelo professor Brasil e encarnada na figura de Cecília Westphalen (1927-2004), teria alterado esse quadro. A partir do final dos anos 1950, na esteira da separação dos cursos de História e de Geografia, e ainda com mais força após a reforma universitária iniciada em 1968, a ênfase recai sobre a pesquisa. A coroação desse processo é a criação do Mestrado em História do Brasil. Compõem o núcleo da série documental aqui mobilizada, além de bibliografia pertinente, as atas da Congregação da FFCL, bem como as atas do Departamento de História e os Anais institucionais. 
A parte seguinte da obra dá densidade à análise da ruptura operada pela segunda geração de professores do curso. No terceiro capítulo, o autor busca mostrar o esforço de Cecília Westphalen e de Altiva Balhana (1928-2009) para produzir uma história quantitativa afinada com correntes historiográficas francesas então em voga. Esses referenciais teóricos foram replicados em um estudo que privilegiava o "regional", evitando ainda qualquer flerte, por menor que fosse, com a perspectiva marxista. Tanto em um trabalho de arrolamento de fontes no Paraná quanto patrocinando a importação de expoentes estrangeiros e a exportação de docentes brasileiros, o curso de História da UFPR transformou-se em uma instituição de referência. O quarto capítulo indica a confluência entre curso e governo federal pós-golpe de 1964. O autor evita as palavras "colaboracionismo", mas enfatiza que a profissionalização do historiador veio aqui responder a demandas de elites políticas, o que permitiu que o curso pudesse funcionar sem sofrer ingerências da repressão, sendo mesmo financeiramente beneficiado. O autor vale-se, então, ao lado da documentação institucional, da análise da produção dos docentes, bem como de entrevistas que lhe foram concedidas por Sergio Nadalin ${ }^{4}$ e Oksana Boruzsenko (1939-2020), professores aposentados do referido curso.

Por fim, os últimos capítulos retomam a dimensão engajada do trabalho: ao mostrar como a profissionalização do historiador se deu em detrimento das preocupações com o ensino, o autor advoga em prol de uma "história pública". Só ela parece estar em condições de exorcizar os fantasmas do passado, tornando as pontes entre universidade e escola novamente transitáveis.

Feito esse sobrevoo, em que destaquei o fio da narrativa e a força dos argumentos do autor, levanto alguns senões em relação à embocadura analítica da obra e à interpretação da série documental que a norteia. Sobre o primeiro ponto, importa questionar-se a própria opção por uma história do "curso de História". Em nenhum momento se explica o que é um "curso", ou mesmo as implicações em torná-lo objeto autônomo de estudo. Antes da Reforma Universitária (1968-1972), o curso era uma entidade pouco palpável, cujo direcionamento dependia dos acordos entre os membros das congregações das faculdades e a administração geral da universidade. Noto ainda que tomavam assento nesses órgãos somente os professores catedráticos e alguns poucos representantes das demais categorias. Na prática, isso significava que as decisões sobre o funcionamento dos cursos existentes, entre eles o de História, dependiam do conjunto dos catedráticos, ligados a múltiplas áreas de 
conhecimento, não estando restritas, portanto, a uma única disciplina. Trata-se, em suma, de um modelo europeu, em sua variante francesa, que após os anos 1960 seria substituído rapidamente por outro, mais afinado com a prática estadunidense, no qual a burocratização se dava por meio dos departamentos, organizados em razão de um ramo do conhecimento particular. Basta observar o currículo do curso de História e Geografia nos anos 1930, 1940 e 1950 para se constatar o peso de áreas que se encontram hoje apartadas umas das outras por invólucros departamentais: filosofia, pedagogia, geografia, sociologia, economia e antropologia. Em nenhum momento a obra em tela considera essa estrutura de engates entre cátedras e congregações, assim como não problematiza o itinerário oferecido aos graduandos. Sem ter uma ideia do (per)curso oferecido aos estudantes, o leitor fica refém de citações isoladas de textos produzidos apenas por catedráticos das cadeiras que nos parecem, hoje, mais próximas da visão que temos do que é o domínio do historiador. Isso reduz o número de porta-vozes do "curso" a três: Bento Munhoz da Rocha (1905-1973), Homero de Barros (1908-1970) e o já mencionado Brasil Pinheiro Machado. Nomes centrais para os estudantes até os anos 1960, como os de José Loureiro Fernandes (1903-1977) e Reinhardt Maack (1892-1969), ou são esquecidos, ou são mencionados apenas en passant.

Note-se ainda que a separação entre História e Geografia não implicou o desaparecimento das congregações e das cátedras. As diversas legislações federais que as extinguiram datam do final dos anos 1960 e só tiveram efeito com o término da Reforma Universitária, já em 1972. É nesse contexto que se cria o Departamento de História em seu formato atual ${ }^{5}$, bem como que se retira do conselho setorial - o qual havia substituído a congregação - prerrogativas relacionadas à base da gestão acadêmica, agora dividida entre departamentos (que criam as disciplinas) e coordenações de curso (que gerenciam o ensino e requisitam aos departamentos a mão de obra necessária para seu funcionamento). Essa divisão definida pela Reforma é crucial, pois impede a sobreposição do "curso" ao "departamento", como o livro analisado sugere em vários momentos. Em resumo, não se é possível ver no livro como a grade do curso muda com o tempo, bem como não se tem uma noção do perfil das pessoas que nele atuavam. Para além dos três catedráticos de primeira hora já citados, faz-se alusão apenas às trajetórias de Cecília Westphalen e de Altiva Balhana, e, ainda assim, com imprecisões e lacunas. Destaco algumas delas.

Com efeito, embora as professoras supramencionadas tenham sido apresentadas como as representantes da geração que apartou ensino e pesquisa, importa lembrar que ambas eram normalistas formadas no Instituto de Edu- 
cação de Curitiba. Além disso, as duas mantiveram, mesmo depois de formadas, anos de ensino em escolas. Não se pode igualmente ignorar seus empenhos em envolver colegas de várias áreas em um projeto voltado a dar dimensão científica aos "estudos sociais", quando já eram pesquisadoras estabelecidas (Machado, 2017). Concordando-se ou não com o projeto, é difícil afirmar que ele ignorava o ensino ou então desprezava a opinião dos professores secundaristas, os quais participaram da empreitada.

O problema maior é, contudo, outro. Ao concentrar a análise em um número muito reduzido de trajetórias, o trabalho ignora o que foi globalmente o ensino de história na UFPR, bem como as tensões inerentes a ele. Não são problematizados, por exemplo, os mecanismos de recrutamento e a atuação dos novos professores. Caso isso tivesse sido feito, ter-se-ia percebido que a maioria das pessoas contratadas entre os anos 1960 e 1980 manteve vínculos com o ensino fundamental e médio. Evitar-se-iam igualmente equívocos quanto ao alinhamento de seus estudantes e professores ao regime militar. Na página 132, o autor afirma que "não houve professores e alunos presos, molestados, exilados, invasão policial, prisão de estudantes ou de professores”. O ano de 1968 foi, contudo, agitado na UFPR. Em maio, em protestos contra o regime, o prédio da reitoria foi ocupado e arrancou-se de seu pátio, pela primeira vez, o busto do ex-reitor e ex-ministro da educação, Flávio Suplicy de Lacerda (1903-1983). Em dezembro, vários discentes foram presos na Chácara do Alemão, quando se reuniam em congresso clandestino da UNE. Entre os detentos estava a então caloura de História Judite Trindade, que permaneceu meses encarcerada e, na sequência, cursou mestrado e doutorado, tendo ainda se tornado professora da UFPR em 1982. Outro professor, Ruy Wachowicz (1936-2000), teve também problemas com o regime. Ele sofreu processo interno por "subversão", e respondeu a interrogatórios dirigidos por militares quanto a seus projetos de pesquisa e textos publicados. Note-se, por fim, que vários historiadores da UFPR, a partir do final dos anos 1970, ajudaram a construir o que mais tarde seria conhecido como o "Movimento dos Professores", grupo que lutou em prol da democratização do ensino superior. Ao reduzir a complexidade do curso a poucas figuras, perde-se tudo isso de vista. Equívocos e esquecimentos históricos são o resultado.

Outro erro grosseiro aparece na página 168, quando se diz que: "o curso de história da UFPR jogou papel indispensável na criação dessa identidade do Paraná: terra de gente loura e de olhos claros". Foi Wilson Martins (19212010), crítico literário e catedrático de língua e literatura francesa na UFPR, quem defendeu tal tese (Martins, 1955). A ideia de um "Brasil diferente" foi 
amplamente contestada por historiadores da mesma instituição. Na primeira metade dos anos 1970, Carlos Antunes dos Santos (1943-2013) e Marcia Graf prepararam dissertações resgatando, a partir de documentação inédita à época, a presença negra no Paraná (Santos, 1974; Graf, 1974). Não deixa de ser irônico lembrar que ambos já eram professores da instituição, e que foram orientados, respectivamente, por Cecília Westphalen e por Altiva Balhana ${ }^{6}$.

Ou seja, parece haver, na costura que sustenta o livro, alguns problemas ocasionados por uma ilusão retrospectiva. Mesmo simpatizando profundamente com as bandeiras nele defendidas, tenho dúvidas sobre se elas ressoam, de fato, no material analisado, ou se não produzem, ao contrário, seu aplainamento. Cria-se assim um bode expiatório que libera as gerações atuais, aquelas que entraram na universidade a partir dos anos 1990, do quinhão de responsabilidade que lhes cabe. Para se restituir isso, seria preciso considerar, antes de mais nada, a expansão descontrolada e desequilibrada, em termos regionais, dos Programas de Pós-graduação, a qual inflacionou o mercado de diplomas e viabilizou uma separação que antes não existia entre as carreiras nos ensinos médio e superior. ${ }^{7}$ Ao contrário das gerações que ingressaram na universidade até o início dos anos 1990, é raro encontrarmos hoje docentes jovens com experiência escolar. Para terem maiores chances de sucesso nos concursos para docente no ensino superior, eles são pressionados a terminar seus cursos o mais rápido possível, e a concentrar todos os seus esforços na produção bibliográfica, bem como na participação em eventos. Soma-se a isso outro desafio adicional: em geral, os concursos levam os aprovados a lugares distantes de onde se formaram, tornando-os inicialmente reféns das redes que constituíram durante seus estudos. Os vínculos com as comunidades locais demoram a ser estabelecidos e são dificultados por exigências da própria vida universitária. Afinal, tão logo entram na universidade, ainda mais em uma unidade dotada de um programa de pós-graduação, eles são submetidos a avaliações estigmatizantes e punitivas. Basta evocar os critérios produtivistas estabelecidos por Comissões de Área da CAPES neste século, os quais ignoram condições locais e colocam os programas uns contra os outros. ${ }^{8}$ Como refletir sobre os desafios da licenciatura e da extensão se devemos produzir ininterruptamente para um público especializado cada vez mais restrito e cada vez menos disponível à leitura dos trabalhos alheios? ${ }^{9} \mathrm{O}$ livro passa longe dessas questões.

A última ressalva recai sobre aspectos formais da obra. Nas páginas 118119, afirma-se: 
O curso não sofria com a ditadura. Apenas a presença da ditadura por meio da Assessoria Especial de Segurança e Informação (AESI) era contestada. Seus agentes eram quase onipresentes na Universidade e, eventualmente, assistiam a aulas e faziam reprimendas. Não havia exatamente uma blindagem, mas alguma alienação dos alunos quanto aos acontecimentos políticos. Não havia professores militantes, era possível acontecerem aulas sobre a História do fascismo, do nazismo, do comunismo sem desconforto. Não havia pesquisas politicamente engajadas. As civilizações ocidentais podiam ser trabalhadas normalmente, facilitadas pelo que ex-professores identificavam na base da bibliografia francesa, consideradas suficientes [sic] para se trabalhar com todos esses temas.

Já indiquei os equívocos históricos inerentes à passagem. Do ponto de vista formal, o problema é que o autor impõe ao leitor a releitura das mesmas frases, sem alterações, nas páginas 136-137. Outro trecho situado entre as páginas 117-118 aparece reproduzido com poucas modificações, via paráfrases, entre as páginas 160-161. Não se trata de casos isolados. O capítulo 6, que se inicia na página 166, tem um início desconjuntado, com uma linguagem de projeto de pesquisa, indicando que serão apresentados resultados já discutidos (“será feito"/"vamos tratar"). Parece ter havido pressa na montagem do trabalho.

De todo modo, o livro tem seus méritos: seu tema é pertinente e ele é fruto de um levantamento documental expressivo, envolvendo ainda entrevistas. Desejo que seu autor não pare por aqui e que possa encorajar produtos análogos. Minhas sugestões aos trabalhos futuros são, em resumo, as seguintes: que se atente mais para o conjunto das populações referidas e para os currículos oferecidos aos estudantes, bem como que se evite comprometer a análise em função de teses pré-concebidas. A tese aqui apresentada, vale repetir, não é nem um pouco desinteressante. Ela espelha, ao contrário, uma questão urgente e fundamental. Mas é cômodo, talvez cômodo demais, forçar a mão para responsabilizar algumas poucas pessoas, em sua maioria já falecidas, por problemas que nós mesmos não cessamos de manter e agravar.

\section{REFERÊNCIAS}

ARAÚJO, Valdei Lopes. A formação do regime de autonomia avaliativo no Sistema Nacional de Pós-graduação e o futuro das relações entre historiografia, ensino e experiência da história. Anos 90, v. 23, n. 44, 2016, p. 85-110.

BENTHIEN, Rafael Faraco. Qualis periódicos na área de história: alguns apontamentos sobre os pressupostos, os resultados e os possíveis efeitos de uma avaliação. In: 
AVILA, Arthur Lima de; NICOLAZZI, Fernando; TURIN, Rodrigo (Orgs.). A História (in)Disciplinada. Vitória: Editora Milfontes, 2019. p. 119-147.

BALHANA, Altiva P.; MACHADO, Brasil P.; WESTPHALEN, Cecília M. História do Paraná. Curitiba: Grafipar, 1969.

BEZERRA, Francisco Chaves. O Ensino Superior de História na Paraíba (1952-1974): aspectos acadêmicos e institucionais. Dissertação (Mestrado em História) - Programa de Pós-Graduação em História, Universidade Federal da Paraíba. João Pessoa, 2007. $140 \mathrm{p}$.

FAGUNDES, Bruno Flávio Lontra. O Auge da História: História do curso de História da Universidade Federal do Paraná. São Paulo: Letra e Voz, 2019. 184 p.

FAGUNDES, Bruno Flávio Lontra. As estórias a favor da história: as Efemérides Mineiras, de José Pedro Xavier da Veiga. Belo Horizonte, Fino Traço, 2014a.

FAGUNDES, Bruno Flávio Lontra. Entre arte e interpretação: figurações do Brasil na literatura de Guimarães Rosa. Tese (Doutorado em História) - Programa de PósGraduação de História, Universidade Federal de Minas Gerais. Belo Horizonte, 2010.

FAGUNDES, Bruno Flávio Lontra. História, historiador e identidade profissional. Sobre a história do Curso de História da Universidade Federal do Paraná. Estudos históricos, Rio de Janeiro, v. 27, n. 54, 2014b, p. 295-315.

FAGUNDES, Bruno Flávio Lontra. Instrução, educação e sentimento nacionais: os Brasis imaginados de José Veríssimo e Guimarães Rosa. Locus: revista de história, Juiz de Fora, v. 17, n. 1, 2011, p. 151-171.

FAGUNDES, Bruno Flávio Lontra. Sobretudo gente da política: sobre a criação do curso de Mestrado em História da Universidade Federal do Paraná em 1972. Patrimônio e Memória, Assis, v. 13, n. 2, 2017,p. 172-197.

FERREIRA, Marieta de Moraes. Os desafios da profissionalização do ensino de História: duas trajetórias de professores universitários. In: ALMEIDA, Marta de; VERGARA, Moema de Rezende (Orgs.). Ciência, história e historiografia. São Paulo: Via Lettera, 2008a. p. 175-189.

FERREIRA, Marieta de Moraes. Perfis e trajetórias dos professores universitários do curso de História no Rio de Janeiro. In: OLIVEIRA, Antônio José Barbosa de. (org.). Universidade e Lugares de Memória. Rio de Janeiro: UFRJ, Sistema de Bibliotecas e Informação, 2008b. p. 235-268.

FERREIRA, Marieta de Moraes. Os professores franceses e o ensino da História no Rio de Janeiro nos anos 30. In: MAIO, Marcos Chor; VILLAS BÔAS, Glaucia (Orgs.). Ideais de Modernidade e Sociologia no Brasil. Ensaios sobre Luiz de Aguiar Costa Pinto. Porto Alegre: Editora da UFRGS, 1999. p. 277-299.

GRAF, Marcia Elisa de Campos. População escrava da Província do Paraná a partir das listas de classificação para Emancipação. 1873-1886. Dissertação (Mestrado em História) - Departamento de História, Universidade Federal do Paraná. Curitiba, 1974. $187 \mathrm{p}$. 
GUEBERT, Caroline Aparecida. Da intelectualidade princesina, o coração do Brasil: trajetória, sociabilidades cívico-letradas e a plasticidade do sertão imaginado no círculo euclidiano. Dissertação (Mestrado em História) - Programa de Pós-Graduação em História, Universidade Federal do Paraná. Curitiba, 2018. 300 p.

MACHADO, Daiane Vaiz. "Perspectivas braudelianas" para o ensino: Cecília Westphalen e o projeto estudos sociais, a partir da longa duração. Interfaces da Educação, Paranaíba, v. 8, n. 22, 2017, p. 8-32.

MACHADO, Daiane Vaiz. Por uma "ciência histórica": o percurso intelectual de Cecília Westphalen, 1950-1998. Tese (Doutorado em História) - Faculdade de Ciências e Letras de Assis, Universidade Estadual Paulista. Assis, 2016. $337 \mathrm{f}$.

MARTINS, Wilson. Um Brasil diferente (ensaio sobre fenômenos de aculturação no Paraná). São Paulo: Editora Anhembi Limitada, 1955.

OHARA, João Rodolfo Munhoz. Virtudes epistêmicas na historiografia brasileira (19801990). Tese (Doutorado em História) - Faculdade de Ciências e Letras de Assis, Universidade Estadual Paulista. Assis, 2017. 151 p.

PORTO, Ana Luiza Araújo. O Curso de História na Universidade Federal de Alagoas: dos primórdios à sua consolidação (1952-1979). Revista Crítica Histórica, v. 1, n. 1, 2010, p. 72-85.

RODRIGUES, Mara Cristina de Matos. A institucionalização da formação superior em história: o curso de Geografia e História da UPA/URGS -1943 a 1950. Dissertação (Mestrado em História) - Instituto de Filosofia e Ciências Humanas, Programa de Pós-Graduação em História, Universidade Federal do Rio Grande do Sul. Porto Alegre, 2002, $222 \mathrm{p}$.

ROIZ, Diogo. Os caminhos (da escrita) da História e os descaminhos de seu ensino: a institucionalização do ensino universitário de História na Faculdade de Filosofia, Ciências e Letras da Universidade de São Paulo. Curitiba: Appris, 2012.

SANTOS, Carlos Roberto Antunes dos. Preços de escravos na Província do Paraná: 1861-1887 (estudo sobre as escrituras de compra e venda de escravos). Dissertação (Mestrado em História) - Curso de Pós-Graduação - Mestrado em História do Brasil, Universidade Federal do Paraná. Curitiba, 1974. 131 p.

WESTPHALEN, Cecília Maria. Situação da pós-graduação em história. Revista de História, v. 55, n. 110, 1977, p. 407-420.

\section{NOTAS}

${ }^{1}$ Destaco aqui, sem ter a ambição e as condições de apresentar uma lista exaustiva, os trabalhos de Francisco Bezerra (2007), Marieta Ferreira (1999), Ana Porto (2010), Mara Cristina de Mattos Rodrigues (2002) e Diogo Roiz (2012).

${ }^{2}$ Penso, em especial, nos trabalhos de Marieta Ferreira (2008a e 2008b), de Daiane Vaiz Machado (2016) e de Caroline Guebert (2018). 
${ }^{3}$ Como, por exemplo, a discussão sobre o desenvolvimento de "virtudes epistêmicas" próprias ao historiador através do estudo de resenhas, necrológios e ensaios proposto por João Rodolfo Munhoz Ohara (2017).

${ }^{4}$ Na página 119, nota 83, a obra indica que Sergio foi "aluno e orientando" de Cecília Westphalen. É uma meia-verdade. Quem o orientou no mestrado foi Altiva Balhana.

${ }^{5}$ O Departamento foi fundado em 1959 , mas como instância para integrar as atividades (de ensino e de pesquisa) das cátedras.

${ }^{6}$ Cecília Westphalen denunciava essa lacuna historiográfica anos antes da defesa dos referidos trabalhos (Balhana; Machado; Westphalen, 1969, p. 119-129). De resto, é fato que a maioria das pesquisas dos docentes remete a imigrantes europeus. Mas, isso não está ligado a uma ideia de "Paraná". Tal fato lança luz sobre os próprios vínculos entre pesquisadores e comunidades. Afinal, aqueles tiraram proveito dos arquivos acumulados por estas, estando ainda a elas ligados. A relevância social desse tipo de trabalho não é desprezível, sobretudo se pensarmos que as colônias eram, então, mais coesas do que são hoje, algumas gerações mais tarde.

${ }^{7}$ Não deixa de ser novamente irônico notar que a própria Cecília Westphalen alertou sobre isso ainda nos anos de 1970 (Westphalen, 1977).

${ }^{8}$ Esses critérios, no tocante à avaliação dos periódicos, foram recentemente discutidos em Benthien, 2019.

${ }^{9}$ Sobre este ponto em particular, veja-se a pertinente avaliação de Araújo, 2016.

Resenha recebida em 10 de setembro de 2020.

Aprovada em 23 de novembro de 2020. 